\title{
Understanding the design variables that contribute to the response of a prosthetic foot: Part I-Rig Design
}

\author{
James Hawkins \\ Department of Design and Engineering \\ Bournemouth University \\ Poole, BH12 5BB, UK \\ james@ridebo.com
}

\author{
Philip Sewell, Mihai Dupac, \\ Department of Design and Engineering \\ Bournemouth University \\ Poole, BH12 5BB, UK \\ psewell@bournemouth.ac.uk
}

\begin{abstract}
In this paper the design of a rig capable to simulate the dynamic response of an energy storing and returning composite prosthetic foot during amputee running is considered. It has been assumed that the amputee/prosthesis system can be modelled as a spring/mass system. Therefore the rig has been designed to allow the applied mass, input force and foot contact point of various feet designs to be varied to test this assumption. The rig will allow the design variables that contribute to the response of a prosthetic foot during running to be understood and optimised to improve the foot's performance.
\end{abstract}

Keywords - prosthetic; foot; displacement; stiffness; running; amputee; boundary conditions; design; optimisation

\section{INTRODUCTION}

Since the commercial introduction of the ESR (Energy Storing and Returning) prosthetic foot in 1985 [1] prosthetists and amputees have been able to choose ever-more specific such as running - and potentially suitable feet for any given application. The action of a runner has successfully long been compared with a spring-mass system and has been shown to accurately predict running mechanics $[2,3,4,5,6,7,8]$. Previously authors $[9,10,11,12]$ have suggested the design of a dynamic response test fixture that aligns with the assumption of a spring-mass system. This means that for the purpose of analysis, the runner and foot makes up a simple spring-mass system (Fig.1) with the intention of establishing a mathematical model for predicting foot response and establishing the design parameters which would lead to a better performing foot.

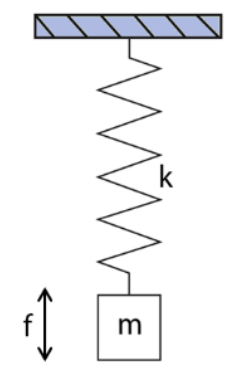

Fig. 1. Ideal spring-mass system where $\mathrm{f}=$ frequency $(\mathrm{Hz})$ of oscillation, $\mathrm{k}=$ spring stiffness $(\mathrm{N} / \mathrm{m})$ and $\mathrm{m}=$ mass $(\mathrm{kg})$
Additional research has been conducted to investigate if a rigid body assumption is valid for running and progressively complex models have been constructed that employ a multitude of mass, spring and damper elements [13, 14, 15, 16, 17]. However as the model becomes more complex it can be seen that the case becomes more specific to an individual and less suitable for predicting the action of a broad spectrum of runners.

As discussed in [18, 19], 'the appropriate foot stiffness selection can reduce the metabolic cost', a view which is shared in $[9,10,11,12]$. If the rig being designed and fabricated possessed the ability to record the timing and magnitude of input energy, this hypothesis could be proven. This could be as simple as a human interaction with the mass, applying a force in a timely manner to match the natural frequency of the system and allow the build-up of an oscillating displacement.

In this paper - assuming validity of a test fixture that aligns with the assumption of a spring-mass system - the design of a rig that simulates a theoretical spring-mass system has been considered (eq.1). Ideally a rig would be fabricated that would allow the reproduction of inputs (mass, deflection amplitude, foot stiffness) as defined by the amputee participant and the output could be compared to that measured during the testing of the participant. Once a correlation between the two systems (amputee and test rig) is established the dynamic behavior of the foot can be assessed. Moreover, a rig would exhibit losses (by means of friction) and as such would require not only an initial excitation but also a source of input energy in order to maintain oscillation of the mass.

$$
f=\frac{1}{2 \pi} \sqrt{\frac{k}{m}}
$$

\section{RIG SPECIFICATION}

In order to simulate the running action of the amputee participant, specifically the action of the prosthetic foot during the course of a single stride, the rig must be defined in a robust manner in keeping with engineering best practice. In summary, the design of the rig must allow for: 
a) Up to $100 \mathrm{~kg}$ mass to be applied safely: The runner used in some previous investigation had a mass of $83.0 \mathrm{~kg}$ [20]. Therefore to replicate their running action the rig should be able to withstand at least this mass to be applied. However in the interest of future testing and examining trends above and beyond the mass of this single amputee, a maximum capacity of $100 \mathrm{~kg}$ was defined. The mass must be held in a stable manner to ensure that the operation of the device is safe for the user.

b) A minimum of $200 \mathrm{~mm}$ vertical displacement above the resting position of the foot: The vertical height achieved by the mass during testing represents the height gained by the centre of mass of the amputee during running [20]. It is important to separate this from the height achieved by the prosthetic foot above the ground as this is influenced by flexion of the knee. Following video examination of amputee running it was deemed sufficient to allow for $200 \mathrm{~mm}$ of vertical travel of the foot ignoring deflection of the foot (the term 'deflection' refers to the change in distance between the shank and distal portion of the foot, whereas 'displacement' refers to the distance travelled by the mass of either the amputee or test rig.)

c) A variety of feet to be attached: Whilst the objective of this investigation is to reproduce the action of the amputee runner, the rig should allow for future testing of other feet from the same and/or alternative manufacturers. There are only two mainstream foot attachment methods for prosthetic ESR running feet (pyramid mount \& posterior mount), examples of these are shown in Fig. 2. The rig should possess the flexibility to adapt to these different mounting styles but not adversely affect the feet on test. They should be able to be mounted in an unintrusive manner that does not require marking or damaging the foot.

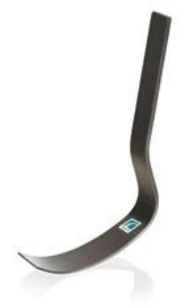

(a)

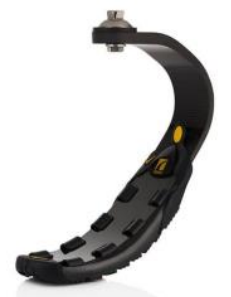

(b)
Fig. 2. Examples of (a) posterior feet, and, (b) pyramid-mounted feet (images source: Ossur.com [21])

d) A minimum calibrated resolution of $+/-1 \mathrm{~mm}$ for displacement/deflection instrumentation, +/-0.1 N for load instrumentation and a minimum logging frequency of $100 \mathrm{~Hz}$ : Any measurements taken from the system must be accurate to allow effective analysis following testing. All instrumentation must be calibrated before testing commences and a minimum logging frequency of $100 \mathrm{~Hz}$ should be used (defined by the limitations of the data acquisition software of the Instron Hydraulic Testing Machine software). The action of a prosthetic running foot is understood to take place primarily in the sagittal plane. In addition, in order to simplify the system to be represented by a basic spring-mass system it is only necessary to allow the mass a single degree of freedom and travel in a purely vertical manner. However it must do so in a free and unrestricted manner in order to minimise any inefficiencies that might influence the results. Theoretically any inefficiency in the rig itself should be identifiable through the analysis of the data collected (by way of hysteresis curves from the force/displacement data).

\section{RIG DESIGN}

\section{A. Basic Design}

A rig was designed, modelled and fabricated as shown in Fig. 3a. Figure 3b. is a front view of the assembled rig and demonstrates the mode of action. Fundamentally this is a vertical sliding motion of a fabricated carriage that is able to securely retain various known cast iron masses that are commonly used in gym equipment, and on the lower edge a prosthetic foot can be mounted. Smooth action of the carriage is ensured with the use of ground linear slide rails with recirculating ball bearings on each side.

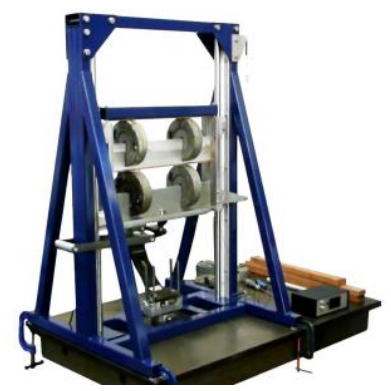

(a)

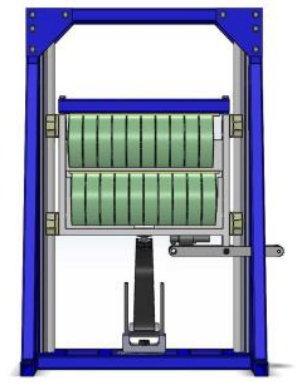

(b)
Fig. 3. (a) manufactured rig, (b) front view of assambled rig design

Oscillation occurs when an input force is momentarily applied to the input handle. Energy is stored in the prosthetic foot and in accordance with the natural harmonic timing of the system is returned as gravitational potential energy. If a significant enough input force is again applied in a timely manner the resulting oscillation of the carriage will increase in amplitude. If the input force is not re-applied the amplitude of oscillation will inevitably decay until movement stops.

\section{B. Mounting of Foot}

The method of mounting the prosthetic foot is critical to ensure meaningful data when undergoing the forced oscillation testing. Most important is to allow the foot the required degrees of freedom at either end where it interfaces with the rig. Over constraint of the foot would result in tension build-up in the rig and this has the potential of adversely affecting the data gathered. The correct mounting of the foot would result in purely vertical forces being applied to the rig in the vertical direction; this means all forces must be compressing the foot into the ground plane. At no point should the rig be subjected to lateral or torsional modes. In order to ensure this:

- all mounting points must be aligned with the vertical centreline of the rig 
- the interface between the rig and foot at both medial and distal ends of the foot must be allowed to rotate in the sagittal plane.

- the distal (toe region) mounting point of the foot must be allowed to leave the ground plane if the energy stored in the system should be sufficient. This is to replicate the foot leaving the ground during amputee running

In order to accommodate for these requirements the foot was mounted using an automotive suspension ball joint at the medial end (at the shank) and between a pair of ball bearing races at the distal end. Importantly the saddle that cradled the ball bearing races at the distal end of the foot was located rigidly on the centerline of the rig and directly below the centre of the ball joint that attached the medial end of the foot to the chassis of the carriage. The ball joint in turn was mounted directly in the centre (in both horizontal and vertical directions) of the base plate of the carriage. This ensured that no lateral or torsional forces could be exerted on the carriage. This arrangement can be seen in the Computer Aided Design (CAD) model shown in Fig. 4a. A side view is shown for clarity in Fig. 4b, with an Ossur Flex Run (category 6Hi) [22] prosthetic foot installed.

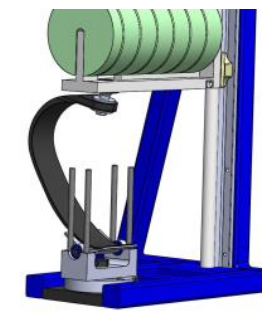

(a)
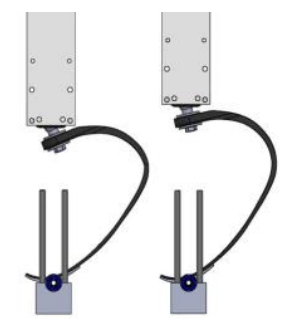

(b)

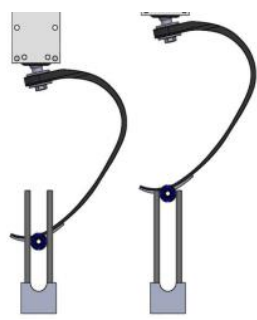

Fig. 4. Examples of posterior and pyramid-mounted feet (images source: Ossur.com [21])

To permit the free movement up away from the ground plane and allow the simulated effect of the runner's foot leaving the ground the bearing races were not captive but instead were cradled in machined cups. If the system possessed enough energy for the foot to leave the ground it was free to do so. However the distal end of the foot (and bearing races) could not deviate from the centreline of the rig because of four guide rods inserted into the bearing cradle, one on each side of each bearing. This arrangement meant that if the bearings left their respective cradles, when the foot dropped again the bearings would return and relocate in their original positions. This action is demonstrated in Fig. 4b. The medial end of the foot could be mounted to the ball joint by simply using the $12 \mathrm{~mm}$ hole provided by the manufacturer for attaching the shank adapter. However the distal end of the foot has no features suitable for attaching any test hardware.

A similar approach to mounting the foot was taken, with the toe of the foot securely held in a purpose-built clamp. The clamp was fabricated from steel and machined such that the bearings were held in place using circlips. It was profiled so not to mark the finish of the foot on test. The clamp with bearings and bearing cradle can be seen in Fig.5. This setup also means that throughout testing the effective ground contact point of the foot remains unchanged. This is important because as the ground contact point of the foot changes so too does the spring rate of the foot.

This approach relies on the bearing races (and associated brackets to clamp the foot) to be attached at the toe, adding an unrepresentative mass. During amputee running it is imperative that this portion of the foot is as lightweight as possible. This is because throughout the course of a single stride the toe of the foot is subject to acceleration from toe-off through the swing phase to foot strike. Additional mass at this location would result in additional energy expenditure by the amputee. However adding mass at this location on the rig is theoretically irrelevant for the purpose of recording the response time of the foot. Firstly this is because the swing phase does not exist (with the foot acting in a purely guided vertical plane). The second reason is that the response timing of the foot is defined by the ground contact time. During this period of ground contact the toe (and associated hardware) is effectively massless, being in contact with the ground plane. The response of the foot is dependent on the mass attached to the shank of the foot instead.

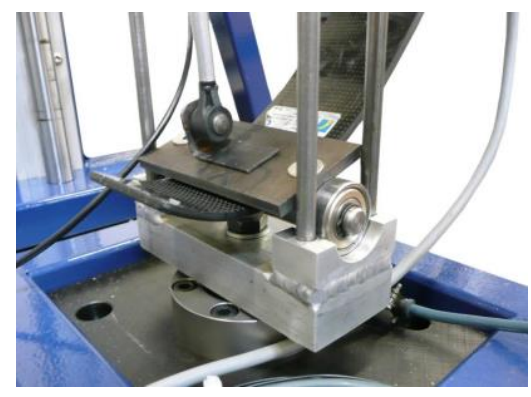

Fig. 5. Photograph of the toe clamp that un-intrusively fixes to the distal portion of the foot and defines the ground contact point. Also visible is the load cell that measures the ground reaction force.

The practical result of this arrangement is that the ground contact point has to be defined prior to any test work being carried out. Below the bearing cradle as can be seen in Fig 5 is the ground force load cell. This load cell is responsible for providing a reading of load going through the foot and is rigidly attached to the bearing cradle using a single screw.

\section{Instrumentation}

Before any calibration work could be conducted the processing circuitry had to be designed and fabricated. The load cells used were of a strain-gauge type with a Wheatstone Bridge contained in each. As such the output is in the order of millivolts (mv), but the desired output for logging using the already available MSR165 data logger was 0-5 volts, meaning that a power source and amplifier circuit was required. A simple operational-amplifier circuit was used for each load cell.

The advantage of this style of amplifier is that the gain can be adjusted by changing resistor values. This means that the working range of the sensor could be manipulated to suit the specific application [23]. For example the ground force load cell used was of a $10 \mathrm{kN}$ capacity. However the maximum force exerted by the rig is never likely to exceed $2.5 \mathrm{kN}$. Therefore in order to improve the resolution of the readings, 
the $0-5 \mathrm{v}$ output from the amplifier circuit could be applied over this $2.5 \mathrm{kN}$ range instead of the full $10 \mathrm{kN}$ range of the load cell. The amplifier circuitry for each channel was then built into a case with a $12 \mathrm{v}$ power supply and a rectifier circuit to change the AC supply from the $12 \mathrm{~V}$ transformer into a stable 12 v DC supply.

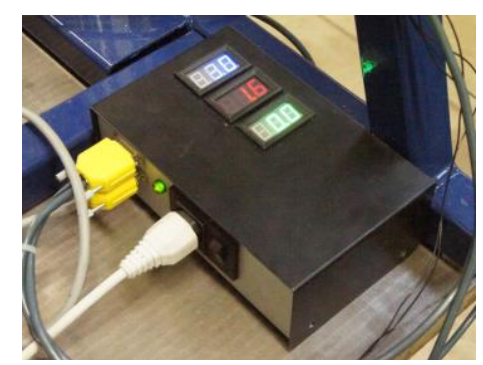

Fig. 6. Amplifier case with output voltages displayed on the lid for each of the three channels requiring amplification.

This case can be seen in Fig. 6. Additional circuitry for the linear resistive displacement transducer (to measure the distance travelled by the mass) was built into the case. All three channels that required amplification (ground reaction force, excitement force and distance travelled by mass) were included in the case and each signal was manipulated to give an approximate $0-5 \mathrm{v}$ output across its working range. Digital volt meter displays were built into the lid of the case meaning that each channel could be monitored without the need for a separate voltmeter (visible in Fig. 6). In order for the dynamic response of the foot to be understood a number of variables should be observed. Details of the needed variables are given in the Table 1.

TABLE I. LIST OF VARIABLES TO BE MEASURED AND THE ASSOCIATED PIECE OF INSTRUMENTATION APPARATUS

\begin{tabular}{|c|c|c|c|c|}
\hline \multirow{2}{*}{$\begin{array}{l}\text { Variable } \\
\text { Name }\end{array}$} & \multicolumn{4}{|c|}{ Table Column Head } \\
\hline & Units & Instrumentation & Manufacturer & $\begin{array}{l}\text { Model \& } \\
\text { Range }\end{array}$ \\
\hline $\begin{array}{l}\text { Mass applied } \\
\text { to the system }\end{array}$ & $\mathrm{Kg}$ & $\begin{array}{l}\text { Ground force } \\
\text { load cell }\end{array}$ & Applied & DSCR \\
\hline $\begin{array}{l}\text { Ground } \\
\text { reaction force }\end{array}$ & $\mathrm{N}$ & $\begin{array}{ll}\text { Ground } & \text { force } \\
\text { load cell } & \end{array}$ & $\begin{array}{l}\text { Measurements } \\
\text { Ltd }\end{array}$ & $10 \mathrm{kN}$ \\
\hline $\begin{array}{l}\text { Excitement } \\
\text { force }\end{array}$ & $\mathrm{N}$ & $\begin{array}{l}\text { Input force load } \\
\text { cell }\end{array}$ & Thames Side & $\begin{array}{c}\mathrm{T} 66 \\
100 \mathrm{~kg}\end{array}$ \\
\hline $\begin{array}{l}\text { Distance } \\
\text { mass traveled }\end{array}$ & $\mathrm{m}$ & $\begin{array}{l}\text { Linear resistive } \\
\text { transducer }\end{array}$ & $\begin{array}{l}\text { In-house } \\
\text { design \& } \\
\text { fabrication }\end{array}$ & $\begin{array}{c}\text { N/A } \\
0-300 \mathrm{~mm}\end{array}$ \\
\hline $\begin{array}{l}\text { Diaplacement } \\
\text { of the foot }\end{array}$ & $\mathrm{m}$ & $\begin{array}{l}\text { Vario-resistive } \\
\text { foot mounted } \\
\text { sensor }\end{array}$ & $\begin{array}{l}\text { Hartmann } \\
\text { Automotive } \\
\text { GmbH }\end{array}$ & $\begin{array}{c}8 \mathrm{~W} 83- \\
3 \mathrm{C} 279- \\
\mathrm{BC} \\
-45^{\circ} /+45^{\circ}\end{array}$ \\
\hline
\end{tabular}

\section{CONCLUSIONS}

The objective of this study was to design and fabricate a rig that was able to mimic amputee running. This would allow individual variables to be modified to improve the understanding of amputee running by recording and manipulating the variables that contribute to the response of the foot and in turn enabling optimisation of the parameters to improve the prosthetic foot's performance. The rig has been designed to closely mimicking the action of an amputee runner during steady-state running, assuming that the following are true:

- the mass of the runner is equivalent to that of the carriage (with masses attached)

- the same (or an identical) foot is used

- the ground reaction force OR foot deflection is copied

- the ground contact point selected to represent the running action is equivalent to that achieved at the point of maximum foot deflection during amputee running (in this case $50 \mathrm{~mm}$ rear of the toe tip)

If these four conditions are satisfied it is expected that this rig can effectively replicate the running action of an amputee runner and return the same ground contact time. However, it has been shown that the ground force maintained by a runner increases at higher velocities $[24,25]$. This change in load will inevitably result in a change in amplitude of deflection of the foot, but it is not yet understood if this change will result in a modified ground contact time. In other words, if the ground contact time changes for different values of foot deflection, the rig can only be used to predict one if the other is known. For example, the ground contact time can be demonstrated if the foot deflection is known and vice versa.

\section{ACKNOWLEDGMENT}

The author has received exceptional support from two specific organizations, Ossur UK for their assistance in understanding their specific prosthetic devices and the supply of a multitude of feet and foot coverings to allow repeatable test work to be conducted, and MSR Electronics GmbH for the supply of their flagship data logger. Thanks must also go to Dr Jan Walter Schroeder and Richard Hawkins Esq. for the design of the electronic circuits used in the various signal amplifiers and conditioner case as detailed in this report.

\section{REFERENCES}

[1] J.W. Michael, "Energy Storing Feet: a clinical comparison", Clinical Prosthetics and Orthotics, 11(3), pp.154-168, 1987.

[2] R. Alexander, "A model of bipedal locomotion on compliant legs", Philosophical Transactions of the Royal Society of London. B 338, pp.189-198, 1992.

[3] R. Blickhan, "The spring-mass model for running and hopping”, Journal of Biomechanics. 22, pp. 1217-1227, 1989.

[4] R. Blickhan, and R.J. Full, "Similarity in multilegged locomotion: bouncing like a monopode", Journal of Comparative Physiology. A 173, pp.509-517, 1993.

[5] C.T. Farley, R. Blickhan, J. Saito, and C.R. Taylor, "Hopping frequency in humans: a test of how springs set stride frequency in bouncing gaits", Journal of Applied Physiology. 716, pp.2127-2132, 1991.

[6] T. McGeer, "Passive bipedal running", Proceedings of the Royal Society of London. B240, pp.107-134, 1990.

[7] T.A. McMahon, G.C. Cheng, "The mechanics of running: how does stiffness couple with speed?”, Journal of Biomechanics. 23(1), pp.65-78, 1990.

[8] A. Seyfarth, H. Geyer, M. Gunther, and R. Blickhan, "A movement criterion for running", Journal of Biomechanics. 35(5), pp.649-655, 2002 . 
[9] J. Lehmann, R. Price, S. Boswell-Bessette, A. Dralle, K. Questad, and B.J. deLateur, "Comprehensive Analysis of Energy Storing Prosthetic Feet: Flex Foot and Seattle Foot Versus Standard SACH Foot", Archives of Physical Medicine \& Rehabilitation. 74(11), pp.1225-1231, 1993.

[10] J. Lehmann, R. Price, S. Boswell-Bessette, A. Dralle, K. Questad, "Comprehensive Analysis of Dynamic Elastic Response Feet: Seattle Ankle/Lite Foot Versus SACH Foot”, Archives of Physical Medicine \& Rehabilitation. 74(8), pp.853-861, 1993.

[11] S. Noroozi, P. Sewell, A.G.A. Rahman, J. Vinney, O.Z. Chao, and B. Dyer, "Performance enhancement of bi-lateral lower-limb amputees in the latter phases of running events: an initial investigation", Journal of Sports Engineering and Technology. 227(2), pp.105-115, 2012.

[12] S. Noroozi, P. Sewell, A.G.A. Rahman, J. Vinney, O.Z. Chao, and B. Dyer, "Modal Analysis of Composite Prosthetic Energy-Storing-andReturning Feet: An Initial Investigation", Journal of Sports Engineering and Technology. 227(1), pp.39-48, 2012.

[13] K.P. Clark, L.J. Ryan, and P.G. Weyand, "Foot speed, foot strike and footwear: linking gait mechanics and running ground reaction forces", Journal of Experimental Biology. 217, pp. 2037-2040, 2014.

[14] W. Liu, B.M. Nigg, "A mechanical model to determine the influence of masses and mass distribution on the impact force during running", Journal of Biomechanics. 33, pp. 219-224, 2000.

[15] Q.H. Ly, A. Alaoui, S. Erlicher, and L. Baly, "Towards a footwear design tool: influence of shoe midsole properties and ground stiffness on the impact force during running", Journal of Biomechanics. 43, pp.310$317,2010$.

[16] B.M. Nigg, and W. Liu, "The effect of muscle stiffness and damping on simulated impact force peaks during running", Journal of Biomechanics. 32, pp.849-856, 1999.

[17] A.A. Nikooyan, and A.A. Zadpoor, "Mass-spring damper modeling of the human body to study running and hopping - an overview",
Proceedings of the Institute of Mechanical Engineers. H 225, pp. 1121$1135,2011$.

[18] K. Lechler, "Lower-Limb Prosthetics - Design Improvements of a Prosthetic Spring Foot", American Journal of Physics. 36, pp. 4-7, 2005.

[19] K. Lechler, and M. Lilja, "Lower extremity leg amputation: an advantage in running?”, Sports Technology. 1(4-5), pp.229-234, 2008.

[20] J. Hawkins, S. Noroozi, M. Dupac, and P. Sewell, “An investigation of the ground contact point and sagittal plane displacement of energy storage and return (ESR) composite lower-limb prosthetic feet during Running. Proceedings of the International Society for Prosthetics \& Orthotics (ISPO) World Congress 2015 22-25 June 2015 Lyon, France. 18 .

[21] Ossur products catalogue, P161. www.ossur.co.uk (Accessed 16th January 2015).

[22] Ossur Instructions for 2012. http://assets.ossur.com/library/25848/FlexRun\%20with\%20Nike\%20Sole_0153_IFU.pdf (Accessed 16th January 2015).

[23] T. Liu, Y. Inoue, and K. Shibata, "Development of a wearable sensor system for quantitative gait analysis", Measurement. 42, pp.978-988, 2009.

[24] C.F. Munro, D.I. Miller, and A.J. Fuglevand, "Ground reaction forces in running: a reexamination”, Journal of Biomechanics. 20(2), pp. 147-155, 1987.

[25] T.S. Keller, A.M. Weisberger, J.L. Ray, S.S. Hasan, R.G. Shiavi, D.M. Spengler, "Relationship between vertical ground reaction force and speed during walking, slow jogging, and running", Clinical Biomechanics. 11(5), pp. 253-259, 1996. 